Published in final edited form as:

J Clin Gastroenterol. 2013 October ; 47(9): 762-768. doi:10.1097/MCG.0b013e318293d522.

\title{
A Cross-sectional Analysis of the Prevalence of Barrett's Esophagus in Otolaryngology Patients with Laryngeal Symptoms
}

\author{
Katie S. Nason, MD MPH ${ }^{1}$, Thomas Murphy, MD ${ }^{1,{ }^{*}}$, Joshua Schindler, MD ${ }^{2}$, Paul H \\ Schipper, MD $^{3}$, Toshitaka Hoppo, MD, PhD7, Brian S Diggs, PhD $^{3}$, David A. Sauer, MD ${ }^{4}$, \\ Nicholas J. Shaheen, MD, MPH ${ }^{5}$, Cynthia D. Morris, PhD MPH $^{6}$, and Blair A. Jobe, MD ${ }^{7}$ \\ ${ }^{1}$ Department of Cardiothoracic Surgery, Division of Thoracic and Foregut Surgery, University of \\ Pittsburgh, Pittsburgh, Pennsylvania \\ ${ }^{2}$ Department of Otolaryngology, Oregon Health \& Science University, Portland, Oregon \\ ${ }^{3}$ Department of Surgery, Oregon Health \& Science University, Portland, Oregon \\ ${ }^{4}$ Department of Pathology, Oregon Health \& Science University, Portland, Oregon \\ ${ }^{5}$ Department of Medicine, Division of Gastroenterology and Hepatology, University of North \\ Carolina, Chapel Hill, North Carolina \\ ${ }^{6}$ Department of Informatics \& Clinical Epidemiology, Oregon Health \& Science University, \\ Portland, Oregon \\ ${ }^{7}$ Department of Surgery, Western Pennsylvania Hospital, West Penn Allegheny Health System, \\ Pittsburgh, Pennsylvania
}

\section{Abstract}

BACKGROUND—Populations at risk for esophageal adenocarcinoma remain poorly defined. Laryngeal symptoms can be secondary to laryngopharyngeal reflux (LPR) and can occur without associated gastroesophageal reflux symptoms such as heartburn and regurgitation.

GOAL-We sought to determine the prevalence of Barrett's esophagus (BE) in otolaryngology patients with laryngeal symptoms \pm typical GERD symptoms.

STUDY -We performed a cross-sectional study of otolaryngology clinic patients who reported laryngeal symptoms. Symptoms, medications and exposure histories were obtained. Unsedated

\footnotetext{
Corresponding Author: Blair A. Jobe, MD, Chief of Surgery, Department of Surgery, Western Pennsylvania Hospital, West Penn Allegheny Health System, 4600 North Tower, 4800 Friendship Avenue, Pittsburgh, PA 15524, Phone: 412-578-4026, Fax: 412-578-1434, bjobe1@wpahs.org.

* Nason and Murphy has shared first authorship. Research Group: Barrett's Esophagus Risk Consortium (BERC)

Publisher's Disclaimer: This is a PDF file of an unedited manuscript that has been accepted for publication. As a service to our customers we are providing this early version of the manuscript. The manuscript will undergo copyediting, typesetting, and review of the resulting proof before it is published in its final citable form. Please note that during the production process errors may be discovered which could affect the content, and all legal disclaimers that apply to the journal pertain.

Presentations: This paper was presented in the poster session of the American Gastroenterological Association/Digestive Disease Week, May 7-10, 2011, Chicago, IL

CONFLICT OF INTEREST: The authors have no conflicts of interest to report.
} 
transnasal endoscopy was performed. Suspected BE was biopsied and confirmed histologically. Risk factors and prevalence of BE were assessed.

RESULTS-Two hundred and ninety five patients were enrolled (73\% male, median age 60 [IQR 51-68]). The overall prevalence of BE was $11.8 \%(n=33)$. Antisecretory medication use was present in $56 \%(\mathrm{n}=156)$ of patients at enrollment. Compared to patients without $\mathrm{BE}$, patients with $\mathrm{BE}$ were more likely to be male ( $\mathrm{p}=0.01)$ and to report occupational lung injury $(\mathrm{p}=0.001)$. Duration, but not severity of laryngeal symptoms, significantly increased the odds of Barrett's esophagus (OR 5.64 [95\% CI 1.28, 24.83] for a duration of symptoms $>5$ years). Of patients with BE, 58\% $(n=19)$ had co-existing LPR and GERD symptoms and 30\% $(n=10)$ had only LPR symptoms. Presence and size of hiatal hernia and length of columnar lined esophagus were significant risk factors for BE.

CONCLUSIONS-Long-standing laryngeal symptoms are associated with the presence of BE in otolaryngology patients. Patients with chronic laryngeal symptoms and no identifiable ear, nose, or throat etiology for those symptoms may benefit from endoscopic screening regardless of whether typical GERD symptoms are present.

\section{Keywords}

Laryngeal symptoms; gastroesophageal reflux disease; screening; otolaryngology; Barreet's esophagus; unsedated transnasal endoscopy

\section{INTRODUCTION}

The association between gastroesophageal reflux disease (GERD), Barrett's esophagus (BE), and esophageal adenocarcinoma (EAC) is well established. Despite efforts to screen patients with chronic symptoms of GERD for BE, the death rate from esophageal cancer has continued to increase exponentially over the past 40 years. ${ }^{1}$ Because chronic typical GERD symptoms have been used as the principal indication for endoscopic screening, the majority of what is known about the prevalence of $\mathrm{BE}$ and its clinical risk factors has been gleaned from highly selected GERD populations. However, up to $50 \%$ of patients that develop EAC do not have an antecedent history of GERD symptoms,${ }^{2}$ leaving the population at risk for $\mathrm{BE}$ and EAC incompletely described. This statement is supported by the fact that the majority of patients who develop EAC have never undergone endoscopic screening for BE prior to cancer diagnosis ${ }^{3}$ and present with dysphagia and advanced disease. ${ }^{4}$ Improved risk stratification for EAC is needed in order to better guide screening efforts, facilitate early stage detection and reduce mortality.

It has been suggested that laryngopharyngeal reflux (LPR) symptoms, including cough, dysphonia, excessive throat clearing and globus sensation are common in patients with $\mathrm{BE}$ and may represent a useful and potent clinical risk factor. ${ }^{5}$ Given that LPR symptoms are highly prevalent and account for $10 \%$ of all outpatient otolaryngology practice visits, ${ }^{6}$ this population represents an unexplored and easily accessible group of patients who are potentially at risk for BE. The aim of this prospective cross-sectional study was to determine the prevalence of BE in an unselected otolaryngology patient population with LPR 
symptoms using a validated technique for unsedated transnasal endoscopy to perform primary screening. ${ }^{7}$

\section{METHODS}

\section{Study Design and Protocol}

This is a cross-sectional study including all non-cancer patients who presented to the general otolaryngology clinics of Oregon Health \& Science University and the Portland Veteran's Administration hospital from February 8, 2005 to June 7, 2007 under the approval of institutional review board of both institutions. At the time of clinic check-in, every patient completed a Reflux Symptom Index (RSI) questionnaire along with his or her intake paperwork (Figure 1). ${ }^{8}$ The RSI is a validated tool that assesses severity of atypical symptoms of GERD, specifically laryngeal symptoms such as hoarseness and cough. ${ }^{9}$ Patients were asked to rate symptoms on a scale of zero (no problem) to 5 (severe problem). Questionnaires were collected and scored by the study coordinator. All subjects who scored greater than 2 in at least two of nine RSI symptom categories, or greater than 3 for any single RSI symptom category were considered eligible and were subsequently contacted by phone and approached for enrollment. A total RSI score $>13$ is defined as abnormal per questionnaire scoring criteria. All enrolled patients underwent primary screening endoscopy using an outpatient and unsedated approach. ${ }^{7}$ Patients with a history of prior screening endoscopy, antireflux surgery, Zenker's or epiphrenic diverticulum, pregnancy, anticoagulation therapy, head and neck malignancy, prior laryngeal surgery or trauma, esophageal varices, vocal cord paralysis, severe medical co-morbidity, or a history of recurrent epistaxis were excluded from study participation.

\section{Demographics and Stratification of Clinical Symptoms}

Detailed demographic data (age, sex, race), medical co-morbidities, allergy, alcohol and tobacco use, current or prior use of anti-secretory medications and body mass index were collected from enrolled patients. Using the GERD Health-Related Quality of Life (GERDHRQL) questionnaire ${ }^{10}$ and Short-Form-12 Health Survey ${ }^{11}$, typical GERD symptoms and overall quality of life were assessed at the time of enrollment. A GERD-HRQL score $>5$ is considered abnormal. Based on questionnaire scores, the clinical symptoms were categorized to 4 groups: no pathologic GERD or LPR (GERD-HRQL $₫$ and RSI $\leq 3$ ), isolated GERD (GERD-HRQL $>5$ and RSI $\leq 13$ ), isolated LPR (GERD-HRQL $\mathbf{5}$ and RSI $>13$ ) and both GERD and LPR (GERD-HRQL >5 and RSI >13).

\section{Technique and Classification of Endoscopic Outcomes}

Patients underwent unsedated transnasal endoscopy as previously described. ${ }^{7,12}$ Using a one-knob, $4.9 \mathrm{~mm}$ diameter flexible endoscope with a $2 \mathrm{~mm}$ working channel (Olympus America Inc., Center Valley, PA), transnasal indirect laryngoscopy was performed and findings such as vocal fold edema, diffuse laryngeal edema and posterior commissure hypertrophy were recorded using the Reflux Finding Score (RFS). ${ }^{9}$ The esophagus was then intubated in coordination with swallowing. Prior to gastric insufflation, the level of the anatomic esophagogastric junction (where the gastric folds meet the tubular esophagus) was compared with the squamocolumnar junction (SCJ) in centimeters from the nares. The 
length of columnar-appearing mucosa protruding into the tubular esophagus was defined as the distance in centimeters from the anatomic esophagogastric junction to the most proximal aspect of the SCJ. The SCJ was assigned a grade based on the ZAP classification. ${ }^{13}$ A ZAP classification of 0 is assigned to a sharp and circular SCJ without tongues of endoscopically visible columnar epithelium; these patients were considered negative for $\mathrm{BE}$ and were not biopsied. A ZAP classification of I is assigned when the SCJ is irregular with slight tonguelike protrusions; a ZAP classification of II exhibits distinct and obvious tongues of columnar epithelium $<3 \mathrm{~cm}$, and a ZAP classification of III has tongues of columnar epithelium $>3 \mathrm{~cm}$ or a cephalad displacement of the SCJ $>3 \mathrm{~cm}$. Patients with a classification of I-III were considered suspicious for BE and were biopsied. Following the Seattle protocol, fourquadrant esophageal biopsies with a $1.8 \mathrm{~mm}$ needle forceps (Olympus America Inc., Center Valley, PA) were obtained beginning immediately proximal to the anatomic esophagogastric junction and extending every $2 \mathrm{~cm}$ to the level of the SCJ. ${ }^{14,15}$ A hiatal hernia was considered present when the anatomic esophagogastric junction was located proximal to the crural pinch, and this separation was measured in centimeters. The presence of esophagitis was documented and scored using the Los Angeles Classification. ${ }^{16}$ The gastric fundus and body were examined and a retroflexion view of the cardia was obtained.

\section{Pathologic Examination and Definition of Barrett's Esophagus}

All tissue specimens were formalin-fixed, paraffin embedded, and stained with hematoxylin and eosin. The diagnosis of BE required that two criteria be fulfilled: 1) endoscopically evident columnar epithelium located within the tubular esophagus thereby triggering a biopsy; and 2) unequivocal presence of goblet cells within columnar epithelium on histologic examination of biopsy specimens. One pathologist with expertise in gastrointestinal pathology examined all biopsy specimens (DAS). When necessary, additional sections were obtained from tissue blocks to facilitate diagnosis. Well-established diagnostic criteria were utilized in the assessment of dysplasia. ${ }^{17}$ Breifly, metaplasia was defined as replacement of normal squamous lining by a glandular lining of the specialized intestinal type, which was charaterized by columnar epithelium containing several cell types such as goblet cells, blue columnar, clear columnar and enterocyte-like cells with brush borders. Low-grade dysplasia (LGD) was characterized by hyperchromatic, enlarged nuclei and depletion of cytoplasmic mucin. High-grade dysplasia (HGD) is characterized by distortion of glandular architecture and dysplastic epithelium on the mucosal surface with loss of nuclear polarity. There is lack of consistent relationship of nuclei to each other. ${ }^{18}$

\section{Data Analysis}

Data are presented as median and inter-quartile range for continuous variables and frequencies for categorical variables. Comparisons of demographic data between groups with and without BE were performed using independent sample t-tests and Mann-Whitney U test for continuous variables and Fischer's exact or chi-squared tests for categorical variables. Univariate and multivariate logistic regression was performed. 


\section{RESULTS}

\section{Patient Demographics and Prevalence of BE}

Overall, 3,170 subjects were assessed for eligibility, and 523 subjects were considered eligible. Of these patients, 295 (56\%) were enrolled after the phone interview and 278 (VA hospital, $\mathrm{n}=151$; University hospital, $\mathrm{n}=127$ ) completed the entire endoscopic examination (Figure 2). Patients were predominantly male $(n=204 ; 73 \%)$ and Caucasian $(n=244 ; 96 \%)$. Mean age and BMI were comparable between the enrollment sites. The overall prevalence of $\mathrm{BE}$ was $11.8 \%(\mathrm{n}=33)$. BE was more prevalent in males $(\mathrm{n}=30 ; 14.7 \%)$ than females $(\mathrm{n}=3 ; 4 \% ; \mathrm{p}=0.014)$. Besides occupational lung injury, there was no difference in lifestyle variables or medical co-morbidities between those with and without BE (Table 1). There was a higher prevalence of $\mathrm{BE}$ at the Veterans Administration hospital compared to the University hospital ( $15.3 \%$ vs. $7.8 \%$, respectively, $\mathrm{p}=0.0053)$. This trend was explained by differences in gender distribution between sites. At the Veterans Administration hospital, $91.4 \%$ of patients were male compared to $51.6 \%$ of patients at the University hospital $(\mathrm{p}=<0.001)$. When only male patients were considered, there was no difference in the prevalence of BE between the two enrollment sites ( $16 \%$ vs. $12 \%, \mathrm{p}=0.471)$. Anti-secretory medication use at the time of enrollment was common $(n=156 ; 56 \%)$ in otolaryngology patients with LPR symptoms and did not differ between patients with and without BE $(\mathrm{p}=0.266)$. Similarly, there was no difference in the duration of anti-secretory medication use between those with and without $\mathrm{BE}(\mathrm{p}=0.712)$.

\section{Endoscopic Findings and Prevalence of BE}

An abnormal Z-line was identified in 142 (51\%) patients (ZAP I, n=93; II, n=31; III, n=18) and all were biopsied (Table 2). Of this group, 31 patients were diagnosed with BE, 2 had low-grade dysplasia, and there were no patients with high-grade dysplasia or invasive cancer. Thirty patients with a ZAP classification of II $(n=23)$ or III $(n=7)$ had a columnarlined tubular esophagus but did not meet diagnostic criteria for BE due to the absence of goblets cells on histologic examination. In 9 of these patients, the length of endoscopic columnar-lined esophagus was $23 \mathrm{~cm}$ (range, 3 to $10 \mathrm{~cm}$ ).

Not surprisingly, the endoscopic length of columnar-appearing mucosa in the esophagus was strongly associated with a BE diagnosis $(\mathrm{p}=0.026)$; of patients with a ZAP classification of III, $61 \%$ had a diagnosis of BE. Hiatal hernia was present in 154 (55\%) patients. Presence of hiatal hernia $(\mathrm{p}=0.015)$ and hiatal hernia size $(\mathrm{p}=0.027)$ were significantly associated with a diagnosis of BE. There was no association between the endoscopic appearance of the larynx $(\mathrm{p}=0.325)$ or the presence of esophagitis $(\mathrm{p}=0.299)$ and a diagnosis of $\mathrm{BE}$ (Table 2). A long duration of LPR symptoms ( $\geq 5$ years) was associated with increased odds of having BE; additionally, patients with a ZAP II or III classification and a long duration of LPR symptoms ( $\geq 5$ years) were even more likely to have BE (OR 9.2; 95\% CI 2.4-36.6) (Table $3)$.

\section{LPR Symptoms and Prevalence of BE}

Overall RSI score did not differ significantly between those with and without a diagnosis of $\mathrm{BE}$, indicating that increasing symptom severity was not associated with the presence of $\mathrm{BE}$ 
(Table 4). Throat clearing $(\mathrm{n}=246 ; 88 \%)$, post-nasal drip $(\mathrm{n}=229 ; 82 \%)$, globus sensation $(n=218 ; 78 \%)$, and hoarseness $(n=214 ; 76 \%)$ were the most prevalent LPR symptoms in the study cohort. Comparing the individual RSI questions between those with BE and without $\mathrm{BE}$, there were no differences in proportions except for cough, which approached significance for being more common in BE patients (OR 2.6, 95\% CI 0.95-6.9). Coexisting cough and hoarseness was common overall $(\mathrm{n}=159,57 \%)$ and more prevalent in BE patients (73\% vs. $55 \% ; \mathrm{p}=0.062)$ (Table 4$)$.

\section{Typical GERD symptoms and Prevalence of BE}

Overall, the median score on the GERD-HRQL at the time of enrollment was 9 (IQR 4-16). The overall GERD-HRQL score was comparable between patients with BE and those without $\mathrm{BE}(\mathrm{p}=0.06$ ). Typical GERD symptoms including heartburn, chest pain, indigestion or regurgitation, were reported concomitantly by $74 \%$ of otolaryngology patients $(n=204)$ (Table 4). There were 10 of 55 patients (18.2\%) with isolated LPR symptoms (i.e., normal GERD-HRQL score and abnormal RSI score) who had BE (Table 5). There was no difference in BE prevalence between those patients who had an abnormal questionnaire score (RSI and/or GERD-HRQL) compared to those with a normal questionnaire score (13.2\% versus $5 \%$, respectively; $\mathrm{p}=0.190)$ (Table 5$)$. When all BE patients $(\mathrm{n}=33)$ were stratified by symptom type, the prevalence of BE was highest in patients with both pathologic GERD and LPR symptoms (58\%) followed by those with isolated LPR (30\%) and then isolated GERD (6\%) (Table 5).

\section{DISCUSSION}

The findings of the present study provide insight into a population of patients likely at risk for $\mathrm{BE}$ and $\mathrm{EAC}$ who would not otherwise be identified for screening under current practices. The BE prevalence in this otolaryngology clinic-based cohort is comparable to that reported for gastroenterology patients with chronic typical symptoms of GERD. ${ }^{19,20}$ Several of the well-established BE risk factors in patients with typical GERD symptoms were also present in otolaryngology patients with laryngeal symptoms. We observed that patients with a long duration of laryngeal symptoms, regardless of symptom severity, were at greatest risk for the presence of BE, similar to the relationship between an increasing duration of heartburn and regurgitation and the prevalence of BE. ${ }^{21}$ In addition, endoscopic markers of reflux disease in patients with LPR symptoms (i.e., presence and size of hiatal hernia, length of columnar-lined epithelium) were also significantly associated with a BE diagnosis. Finally, there was no correlation between the endoscopic appearance of the larynx and the presence of BE.

One of the primary challenges encountered in the effort to improve EAC risk stratification, has been the lack of correlation between symptom severity and cancer risk ${ }^{22}$; patients are more likely to seek medical care and ultimately be chosen for endoscopic screening if their symptoms are severe and poorly controlled. However, many patients have abnormal esophageal exposure to gastric juice in the face of mild or absent GERD symptoms. In the present study, it is likely that heartburn was either entirely absent or controlled with medical therapy, and the only manifestation of continued pathologic reflux was the LPR symptoms 
that ultimately triggered otolaryngology consultation., ${ }^{2,23}$ The results of the present study support that no questionnaire or single symptom score, serving as an indicator of severity, will aid in diagnosis of BE; we should instead focus our efforts on the identification of symptom category (i.e., LPR and/or GERD) and duration. Given that BE was more prevalent in those with LPR symptoms (with or without co-existing GERD) compared to those with isolated GERD symptoms, otolaryngology patients with a long duration of symptoms in the absence of an ear, nose or throat etiology could be a potential candidate for screening endoscopy, particularly if these patients are taking proton pump inhibitors.

There is controversy as to whether biopsies should be obtained from an irregular Z-line (ZAP classification I) as well as the oncologic significance of ultra short-segment BE. ${ }^{24}$ For thoroughness, we biopsied all abnormal appearing squamocolumnar junctions based on established criteria ${ }^{14}$; this action accounted for 14 of the 33 patients with BE and may have resulted in over-diagnosis, which is a potential limitation of the present study. However, if only patients with a ZAP classification greater than I were considered to be true BE, the prevalence was $7 \%$ in this previously unscreened population; a prevalence that is comparable to screening studies for BE in patients with chronic GERD. ${ }^{25,26}$

This study has characteristics that may limit generalizability of the findings. First, we successfully enrolled only $56 \%$ of eligible subjects, and it is possible that patients who agreed to participate were more likely to have long standing GERD symptoms that made them more willing to be enrolled, although "duration" of symptoms was defined based on information provided by subjects, potentially leading to recall bias. Despite this possibility of selection and recall bias, these patients had never undergone a prior screening endoscopy and the BE would have remained undetected. These findings likely recapitulate a "real world" scenario where patients have medical control of heartburn but continue to have fullcolumn reflux events and present with predominate LPR symptoms. Long-segment columnar-lined esophagus without goblet cells was identified in 9 patients. Several studies have demonstrated that while the sample size is smaller with transnasal endoscope obtained biopsies, there is an equivalent histologic yield compared to biopsies obtained with the conventional sedated approach ${ }^{27,28}$; however it is possible that the needle forceps used in the present study ( $1.9 \mathrm{~mm}$ in diameter) may result in the smaller biopsy specimens, and additional biopsies would have revealed goblet cells in some of these patients, therefore underestimating the prevalence of BE. Finally, the populations of patients approached for enrollment were recruited from University and VA general otolaryngology clinics, and may not reflect the 'general population' of patients with laryngeal symptoms. ${ }^{20}$ When analyzed by institution and controlled for gender, no differences in either prevalence or associated clinical risk factors were identified, suggesting that institutional differences between the patient populations were minor with respect to our outcomes of interest.

In summary, we have found a high prevalence of BE in otolaryngology patients with laryngeal symptoms. These patients may represent a significant subset of patient in whom advanced EAC develops without a history of GERD or medically treated GERD. Importantly, the patients recruited for this study represent a population for which endoscopic screening would not have been recommended. Given that over $90 \%$ of subjects developing 
esophageal adenocarcinoma do not have a preceding diagnosis of $\mathrm{BE},{ }^{3}$ this subset of patients represents a promising target for cancer prevention strategies.

\section{Acknowledgments}

Grant Support: This study was supported in-part by the David E. Gold and Irene Blumenkranz Esophageal Cancer Research Fund (BAJ), Michael J. Newton Esophageal Cancer Foundation (BAJ), Robert Anthony McHugh Research Fund for the Prevention and Early Detection of Esophageal Cancer (BAJ) and National Institutes of Health grants UL1 RR024140, UL1 RR024153, K23 DK066165-01 (BAJ), R21 DK081161-01 (BAJ), and U01 DK57132.

\section{References}

1. Pohl H, Welch HG. The role of overdiagnosis and reclassification in the marked increase of esophageal adenocarcinoma incidence. J Natl Cancer Inst. 2005; 97:142-146. [PubMed: 15657344]

2. Lagergren J, Bergstrom R, Lindgren A, et al. Symptomatic gastroesophageal reflux as a risk factor for esophageal adenocarcinoma. N Engl J Med. 1999; 340:825-831. [PubMed: 10080844]

3. Dulai GS, Guha S, Kahn KL, et al. Preoperative prevalence of Barrett's esophagus in esophageal adenocarcinoma: a systematic review. Gastroenterology. 2002; 122:26-33. [PubMed: 11781277]

4. Jemal A, Siegel R, Ward E, et al. Cancer statistics, 2009. CA Cancer J Clin. 2009; 59:225-249. [PubMed: 19474385]

5. Reavis KM, Morris CD, Gopal DV, et al. Laryngopharyngeal reflux symptoms better predict the presence of esophageal adenocarcinoma than typical gastroesophageal reflux symptoms. Ann Surg. 2004; 239:849-856. discussion 856-848. [PubMed: 15166964]

6. Koufman JA. The otolaryngologic manifestations of gastroesophageal reflux disease (GERD): a clinical investigation of 225 patients using ambulatory 24-hour $\mathrm{pH}$ monitoring and an experimental investigation of the role of acid and pepsin in the development of laryngeal injury. Laryngoscope. 1991; 101:1-78. [PubMed: 1895864]

7. Jobe BA, Hunter JG, Chang EY, et al. Office-based unsedated small-caliber endoscopy is equivalent to conventional sedated endoscopy in screening and surveillance for Barrett's esophagus: a randomized and blinded comparison. Am J Gastroenterol. 2006; 101:2693-2703. [PubMed: 17227516]

8. Belafsky PC, Postma GN, Koufman JA. Validity and reliability of the reflux symptom index (RSI). J Voice. 2002; 16:274-277. [PubMed: 12150380]

9. Belafsky PC, Postma GN, Koufman JA. The validity and reliability of the reflux finding score (RFS). Laryngoscope. 2001; 111:1313-1317. [PubMed: 11568561]

10. Velanovich V, Vallance SR, Gusz JR, et al. Quality of life scale for gastroesophageal reflux disease. J Am Coll Surg. 1996; 183:217-224. [PubMed: 8784314]

11. Ware J Jr, Kosinski M, Keller SD. A 12-Item Short-Form Health Survey: construction of scales and preliminary tests of reliability and validity. Med Care. 1996; 34:220-233. [PubMed: 8628042]

12. Peery AF, Hoppo T, Garman KS, et al. Feasibility, safety, acceptability, and yield of office-based, screening transnasal esophagoscopy (with video). Gastrointestinal endoscopy. 2012; 75:945-953. e942. [PubMed: 22425272]

13. Wallner B, Sylvan A, Janunger KG. Endoscopic assessment of the "Z-line" (squamocolumnar junction) appearance: reproducibility of the ZAP classification among endoscopists. Gastrointest Endosc. 2002; 55:65-69. [PubMed: 11756917]

14. Levine DS, Haggitt RC, Blount PL, et al. An endoscopic biopsy protocol can differentiate highgrade dysplasia from early adenocarcinoma in Barrett's esophagus. Gastroenterology. 1993; 105:40-50. [PubMed: 8514061]

15. Reid BJ, Blount PL, Feng Z, et al. Optimizing endoscopic biopsy detection of early cancers in Barrett's high-grade dysplasia. The American journal of gastroenterology. 2000; 95:3089-3096. [PubMed: 11095322]

16. DiBaise JK. The LA classification for esophagitis: a call for standardization. The American journal of gastroenterology. 1999; 94:3403-3404. 
17. Mueller J, Werner M, Stolte M. Barrett's esophagus: histopathologic definitions and diagnostic criteria. World J Surg. 2004; 28:148-154. [PubMed: 14727064]

18. Montgomery E, Bronner MP, Goldblum JR, et al. Reproducibility of the diagnosis of dysplasia in Barrett esophagus: a reaffirmation. Human pathology. 2001; 32:368-378. [PubMed: 11331953]

19. Hirota WK, Loughney TM, Lazas DJ, et al. Specialized intestinal metaplasia, dysplasia, and cancer of the esophagus and esophagogastric junction: prevalence and clinical data. Gastroenterology. 1999; 116:277-285. [PubMed: 9922307]

20. Gerson LB, Shetler K, Triadafilopoulos G. Prevalence of Barrett's esophagus in asymptomatic individuals. Gastroenterology. 2002; 123:461-467. [PubMed: 12145799]

21. Eisen GM, Sandler RS, Murray S, et al. The relationship between gastroesophageal reflux disease and its complications with Barrett's esophagus. Am J Gastroenterol. 1997; 92:27-31. [PubMed: 8995932]

22. Nason KS, Wichienkuer PP, Awais O, et al. Gastroesophageal reflux disease symptom severity, proton pump inhibitor use, and esophageal carcinogenesis. Archives of surgery. 2011; 146:851858. [PubMed: 21768433]

23. Frazzoni M, Savarino E, Manno M, et al. Reflux patterns in patients with short-segment Barrett's oesophagus: a study using impedance-pH monitoring off and on proton pump inhibitor therapy. Alimentary pharmacology \& therapeutics. 2009; 30:508-515. [PubMed: 19519732]

24. Clark GW, DeMeester TR. Biopsy of upper gastrointestinal tract lesions. Indications and clinical significance. Surgical oncology clinics of North America. 1995; 4:81-102. [PubMed: 7697461]

25. Fouad YM, Makhlouf MM, Tawfik HM, et al. Barrett's esophagus: prevalence and risk factors in patients with chronic GERD in Upper Egypt. World journal of gastroenterology : WJG. 2009; 15:3511-3515. [PubMed: 19630106]

26. Gilbert EW, Luna RA, Harrison VL, et al. Barrett's esophagus: a review of the literature. Journal of gastrointestinal surgery : official journal of the Society for Surgery of the Alimentary Tract. 2011; 15:708-718. [PubMed: 21461873]

27. Craig A, Hanlon J, Dent J, et al. A comparison of transnasal and transoral endoscopy with smalldiameter endoscopes in unsedated patients. Gastrointestinal endoscopy. 1999; 49:292-296. [PubMed: 10049410]

28. Dumortier J, Ponchon T, Scoazec JY, et al. Prospective evaluation of transnasal esophagogastroduodenoscopy: feasibility and study on performance and tolerance. Gastrointestinal endoscopy. 1999; 49:285-291. [PubMed: 10049409] 
Within the last MONTH, how did the following problems affect you?

Hoarseness or a problem with your voice

Clearing your throat

Excess throat mucous

Difficulty swallowing food, liquid or pills

Coughing after eating or after lying down

Breathing difficulties or choking episodes

Troublesome or annoying cough

Sensations of something sticking in your throat or a lump in your throat

Heartburn, chest pain, indigestion, or stomach

acid coming up
$0=$ No problem

$5=$ Severe problem

Figure 1.

Reflux Symptom Index. Patients were asked to rate symptoms on a scale of zero (no problem) to 5 (severe problem). All subjects who scored greater than 2 in at least two of nine RSI symptom categories, or greater than 3 for any single RSI symptom category were considered eligible in this study. A total RSI score $>13$ is defined as abnormal per questionnaire scoring criteria. 


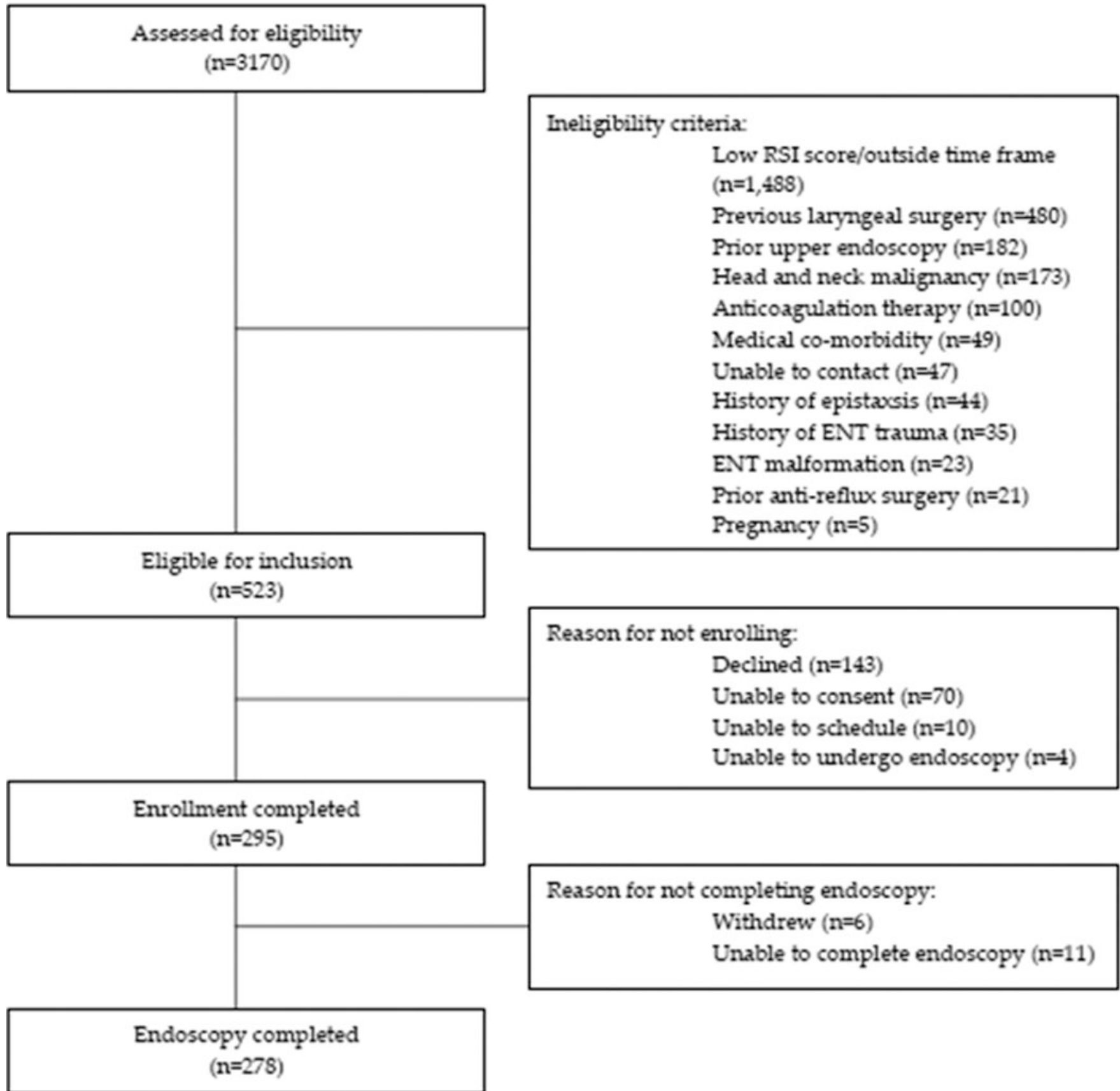

Figure 2.

Flow chart of subject Screening, eligibility and study completion 


\section{Table 1}

Patient demographics, lifestyle variables and co-morbidities

\begin{tabular}{|c|c|c|c|c|}
\hline Characteristic & $\begin{array}{c}\text { Total } \\
\mathbf{n}=\mathbf{2 7 8}\end{array}$ & $\begin{array}{l}\text { BE Negative } \\
\mathbf{n}=\mathbf{2 4 5} \text { (88) }\end{array}$ & $\begin{array}{c}\text { BE Positive } \\
\mathbf{n}=33(12)\end{array}$ & p-value \\
\hline Male sex & $204(73)$ & $174(71)$ & $30(91)$ & $0.014 *$ \\
\hline Age [median (IQR)] & $60(51-68)$ & $60(50-67)$ & $59(52-72)$ & 0.07 \\
\hline BMI [median (IQR)] & $28.5(25-32)$ & $28.3(25-32)$ & $28.7(25-31)$ & 0.94 \\
\hline Caucasian Race & $244(96)$ & $214(96)$ & $30(97)$ & 0.75 \\
\hline Typical GERD symptoms ever? & $219(79)$ & $193(79)$ & $26(79)$ & 0.97 \\
\hline \multicolumn{5}{|l|}{ Cigarette Smoking } \\
\hline Never & $104(37)$ & $95(39)$ & $9(27)$ & 0.423 \\
\hline Former & $134(48)$ & $115(47)$ & $19(58)$ & \\
\hline Current & $41(15)$ & $35(15)$ & $5(15)$ & \\
\hline Current Alcohol Use & $144(52)$ & $125(51)$ & $19(59)$ & 0.386 \\
\hline \multicolumn{5}{|l|}{ Co-morbidities } \\
\hline Diabetes & $36(13)$ & $33(14)$ & $3(8)$ & 0.482 \\
\hline COPD & $22(8)$ & $18(7)$ & $4(12)$ & 0.344 \\
\hline Asthma & $66(24)$ & $60(25)$ & $6(19)$ & 0.452 \\
\hline Occupational lung injury & $70(26)$ & $54(23)$ & $16(50)$ & $0.001^{*}$ \\
\hline Seasonal allergy & $93(34)$ & $83(34)$ & $10(32)$ & 0.822 \\
\hline Current Antisecretory medication use & $156(56)$ & $138(56)$ & $18(55)$ & 0.266 \\
\hline \multicolumn{5}{|l|}{ Duration of medication use } \\
\hline$<6$ months & $68(35)$ & $60(35)$ & $8(40)$ & \\
\hline $6-12$ months & $18(9)$ & $15(9)$ & $3(15)$ & \\
\hline $1-2$ years & $39(20)$ & $37(22)$ & $2(10)$ & 0.712 \\
\hline $3-5$ years & $35(18)$ & $31(18)$ & $4(20)$ & \\
\hline$>5$ years & $32(17)$ & $29(17)$ & $3(15)$ & \\
\hline Never used & $84(30)$ & $71(29)$ & $13(39)$ & 0.268 \\
\hline
\end{tabular}

All values are reported as the number of patients (n) and percent (\%) unless otherwise stated IQR: interquartile range, BMI: body mass index, COPD: chronic obstructive pulmonary disease

p-value $<0.05$ was considered significant. 
Table 2

Endoscopic findings in otolaryngology patients with LPR symptoms undergoing primary screening

\begin{tabular}{|l|c|c|c|c|}
\hline Endoscopic Findings & $\begin{array}{c}\text { BE Negative } \\
(\mathbf{n = 2 4 5})\end{array}$ & $\begin{array}{c}\text { BE Positive } \\
(\mathbf{n}=\mathbf{3 3})\end{array}$ & p-value & $\begin{array}{c}\text { Crude OR (95\% } \\
\text { CI) }\end{array}$ \\
\hline Zap Classification [n (\%)] & & & & \\
\hline Grade 0 & $135(100)$ & $0(0)$ & & \\
\hline Grade I & $79(85)$ & $14(15)$ & & \\
\hline Grade II & $23(74)$ & $8(26)$ & & \\
\hline Grade III & $7(39)$ & $11(61)$ & & \\
\hline Length of CLE (cm) [median (IQR)] & $0(0-1)$ & $1(1-3)$ & $\mathbf{0 . 0 2 6}^{*}$ & $2.1(1.5,2.8)^{a}$ \\
\hline Hiatal hernia [n (\%)] & $129(53)$ & $25(76)$ & $\mathbf{0 . 0 1 5}$ & $2.7(1.2,6.3)$ \\
\hline Hiatal hernia size (cm) [median (IQR)] & $1(0-1)$ & $2(1-3)$ & $\mathbf{0 . 0 2 7}$ & $1.3(1.0,1.6)^{a}$ \\
\hline Abnormal RFS [median (IQR)] & $10(7-14)$ & $10(8-14)$ & 0.341 & $1.0(0.96,1.1)^{b}$ \\
\hline Presence of esophagitis [n (\%)] & $65(27)$ & $12(36)$ & 0.300 & $1.6(0.7,3.4)$ \\
\hline
\end{tabular}

${ }^{a}$ For each $1 \mathrm{~cm}$ increase in length of hiatal hernia or length of CLE

${ }^{b}$ For each 1 point increase in the reflux findings score, GERD-HRQL, and reflux symptom index IQR=interquartile range; CLE=columnar lined esophagus; RFS=reflux finding score

p-value $`<0.05$ was considered significant 
Table 3

Association between ZAP classification, duration of LPR symptoms and Barrett's esophagus

\begin{tabular}{|l|c|c|c|c|}
\hline $\begin{array}{l}\text { LPR symptom duration by } \\
\text { ZAP classification }\end{array}$ & All Patients & Negative BE & Positive BE & $\begin{array}{c}\text { Odds Ratio } \\
\mathbf{9 5 \%} \text { CI })\end{array}$ \\
\hline Overall & $\mathrm{n}=278$ & $\mathrm{n}=245$ & $\mathrm{n}=33^{\dagger}$ & \\
\hline$<5$ years & $189(68)$ & $176(72)$ & $13(39)$ & \\
\hline 25 years & $89(32)$ & $69(28)$ & $20(61)$ & $3.9(1.9,8.3)$ \\
\hline ZAP I or higher & $\mathrm{n}=124$ & $\mathrm{n}=92$ & $\mathrm{n}=32$ & \\
\hline$<5$ years & $80(65)$ & $67(73)$ & $13(41)$ & \\
\hline 25 years & $44(35)$ & $25(27)$ & $19(59)$ & $4.5(2.0,10.1)$ \\
\hline ZAP II or III & $\mathrm{n}=42$ & $\mathrm{n}=24$ & $\mathrm{n}=18$ & \\
\hline$<5$ years & $24(57)$ & $19(79)$ & $5(28)$ &. \\
\hline 25 years & $18(43)$ & $5(21)$ & $13(72)$ & $9.2(2.4,36.6)$ \\
\hline
\end{tabular}

${ }^{\dagger}$ Histologic intestinal metaplasia $(\mathrm{n}=31$ ) or low-grade dysplasia $(\mathrm{n}=2)$. There were no patients with high-grade dysplasia or invasive cancer 
Table 4

Comparison of symptoms between patients with and without BE

\begin{tabular}{|l|c|c|c|c|}
\hline & $\begin{array}{c}\text { Negative BE } \\
(\mathbf{n = 2 4 5})\end{array}$ & $\begin{array}{c}\text { Positive BE } \\
(\mathbf{n = 3 3})\end{array}$ & p-value & Crude OR (95\% CI) \\
\hline Reflux Symptom Index (RSI) & $19(13-26)$ & $22(15-27)$ & 0.515 & $1.0(0.98,1.1)^{\dagger \dagger}$ \\
\hline LPR symptoms & & & & \\
\hline Throat clearing & $216(88)$ & $28(85)$ & 0.573 & $0.75(0.27,2.1)$ \\
\hline Post-nasal drip & $199(81)$ & $79(88)$ & 0.471 & $1.7(0.56,5.0)$ \\
\hline Globus sensation & $190(78)$ & $26(79)$ & 1.000 & $1.1(0.44,2.6)$ \\
\hline Hoarseness & $183(75)$ & $29(88)$ & 0.126 & $2.5(0.83,7.3)$ \\
\hline Troublesome cough & $168(69)$ & $28(85)$ & 0.067 & $2.6(0.95,6.9)$ \\
\hline Cough \& hoarseness & $135(55)$ & $24(73)$ & 0.062 & $2.2(0.97,4.9)$ \\
\hline GERD-HRQL score & $9(3.5-16)$ & $9(4-12)$ & 0.060 & $(0.92,1.0)^{\dagger \dagger}$ \\
\hline Typical GERD symptoms & $180(74)$ & $24(73)$ & 1.000 & $0.96(0.43,2.2)$ \\
\hline
\end{tabular}

${ }^{\dagger \dagger}$ For each 1 point increase in the reflux findings score, GERD-HRQL, and reflux symptom index RSI and GERD-HRQL scores are provided as median (interquartile range) 
Table 5

Association between symptom type and prevalence of BE

\begin{tabular}{|l|c|c|c|c|}
\hline & \multicolumn{2}{|c|}{$\begin{array}{c}\text { All patients } \\
(\mathbf{n = 2 7 4})\end{array}$} & $\begin{array}{c}\text { Patients with BE } \\
(\mathbf{n = 3 3})\end{array}$ & $\begin{array}{c}\text { Patients without } \\
\text { BE (n=241) }\end{array}$ \\
\hline Symptom Type & Total & $\begin{array}{c}\text { BE Prevalence } \\
{[\mathbf{n}(\%)]}\end{array}$ & \multicolumn{2}{|c|}{$\begin{array}{c}\text { Distribution of Symptom type } \\
\text { [n (\%)] }\end{array}$} \\
\hline Abnormal questionnaire score & 234 & $31(13.2)$ & $31(94 \%)$ & $203(84 \%)$ \\
\hline Mixed GERD and LPR & 147 & $19(12.9)$ & $19(58 \%)$ & $128(53 \%)$ \\
\hline Isolated LPR & 55 & $10(18.2)$ & $10(30 \%)$ & $45(19 \%)$ \\
\hline Isolated GERD & 32 & $2(6.3)$ & $2(6 \%)$ & $30(12 \%)$ \\
\hline Normal questionnaire score & & & & \\
\hline No pathological GERD or LPR & 40 & $2(5)$ & $2(6 \%)$ & $38(16 \%)$ \\
\hline
\end{tabular}

GERD: Gastroesophageal reflux disease, LPR: laryngopharyngeal reflux, BE: Barrett's esophagus

Isolated GERD: Abnormal GERD-HRQL score with normal RSI score

Isolated LPR: Abnormal RSI score with normal GERD-HRQL score. 